\title{
Modified Alcohol Oxidase Method Used to Determine the Degree of Pectin Methylesterification
}

\author{
Yasushi Matsuura, ${ }^{1}$ Kiminori Matsubara, ${ }^{2}$ Atsuko SaSAKI' and Michiko FuChIGAMI ${ }^{2 *}$ \\ 'Department of Human Nutrition, Chugokugakuen University, Niwase, Okayama 701-0197, Japan \\ ²Department of Nutritional Science, Okayama Prefectural University, Soja 719-1197, Japan
}

Received August 29, 2003; Accepted December 19, 2003

\begin{abstract}
The degree of methylesterification of pectin was measured using a modified alcohol oxidase method to determine the methanol liberated from pectin by saponification. When the alcohol oxidase method was used to determine the degree of methylesterification from crude pectin extracted from raw vegetables, the colorimetric determination value was thought to be low compared with the net value. From this result it was hypothesized that crude pectin contained some substance which had a reduction effect (inhibitory factor) on the determination value. This inhibitory factor could be removed by the addition of a copper sulfate in the alkaline condition. Two alcohol oxidase methods were applied to investigate a method to determine the degree of methylesterification of pectin; one was the method reported by Hamano et al. (1990) and the other was that reported by Klavons \& Bennett (1986). The determination value of the two methods agreed when a copper sulfate was added.
\end{abstract}

Keywords: methylesterification, spectrophotometry, determination, alcohol oxidase, methanol, pectin, vegetables

Pectin is a primary component of the middle lamella of plant cell walls. It contributes to the adhesion of the parenchyma cells of vegetables and fruit and the mechanical strength of tissue between the cells. Carboxyl groups of galacturonic acid residue composed of pectin are esterified with methoxyl groups. The physicochemical characteristics of pectin are controlled by the degree of esterification and the distribution of methylester groups (Prakash \& Brinson, 1984). The free carboxyl groups of pectin can be cross-linked by salt bridges with divalent metal ions leading to the formation of gel (Braccini \& Perez, 2001) resulting in a firmer texture for vegetables and fruit.

Linkages $(\alpha-1,4-)$ of the galacturonic acid residues in pectin are broken down by $\beta$-elimination reaction at room temperature in an alkaline solution, or they are broken down by heating in a neutral $\mathrm{pH}$ solution. The chemical $\beta$-elimination reaction has been previously studied (Albersheim et al., 1960; Kravtchenko et al., 1992; Renard \& Thibault, 1996). The $\beta$-elimination reaction requires a methylated carboxyl group, and more recently it has been reported that two adjacent methylesters may be necessary for this reaction (Renard \& Thibault, 1996). Therefore, this methylesterification affects the softening of vegetables during cooking. Vegetables, which are easily softened by thermal treatment, contain more rather than less methoxyl pectin (Fuchigami, 1987). However, low temperature treatment (for example, at $60^{\circ} \mathrm{C}$ ) of vegetables causes hardness of tissue by activating pectin methylesterase leading to increased metal ion cross-linking (Bartolome \& Hoff, 1972b; Hou \& Chang,

*To whom correspondence should be addressed.

E-mail: fuchigam@fhw.oka-pu.ac.jp
1996). Also, the de-esterification of pectin in vegetables by preheating at $60^{\circ} \mathrm{C}$ prevents $\beta$-elimination of pectin during cooking (Fuchigami, 1986).

The degree of pectin methylesterification has previously been determined by titration (McColloch \& Kertesz, 1947; Lee \& Macmillan, 1968), spectrophotometry (Hatanaka \& Ozawa 1966), gas chromatography (Bartolome \& Hoff, 1972a; McFeeters \& Armstrong, 1984), and the HPLC-method (Voragen et al., 1986). In 1980, a method to determine methanol was developed by Compton and Purdy (1980). The technique is sensitive to spectrophotometrical and/or spectrofluorimetrical methods that determine the coloring matter which is formed by the reaction of 4-amino-3-penten-2-one (Fluoral-P) and formaldehyde from methanol. Hamano et al. (1990) applied this method to determine the methoxyl group of aspartame (Laspartyl-L-phenylalanine methyl ester). Prior to Hamano et al., Klavons and Bennett (1986) presented a means of determining a methoxyl group in purified pectin using alcohol oxidase, and they stated that this method was sensitive and accurate. The method of Wojiciechowski and Fall (1996) is also an alcohol oxidase method used to determine methylesterase activity. However, the conditions for the determination of the methylesterification of pectin were not investigated.

During the preliminary stage of this experiment, we found that when the methylester content of crude pectin (extracted from vegetables) was determined by an alcohol oxidase method, the degree of methylesterification was lower than that found in previous research where the degree of methylesterification was interpreted to be about $60-80 \%$. For example, apple pectin is $74.3 \%$ and citrus pectin is $72.1 \%$ (Voragen et al., 1995). From these results it appears that the crude pectin from 
certain plants (i.e., radish, cabbage, carrot and broccoli) contains some substance (inhibitory factor) which decreases the determined values. We hypothesize that the inhibitory factor may be removed by the addition of copper sulfate to the alkaline-hydrolysates of crude pectin, which is extracted from raw vegetables, through precipitation of pectic acid and copper hydroxide. This idea was introduced in a description when copper sulfate was added to remove pectic acid under an acidic condition (Hatanaka \& Ozawa, 1966).

Thus, the first objective of this study was to demonstrate that an inhibitory factor is present in crude pectin extracted from vegetables. The second objective was to establish a more sensitive and spectrophotometric method to determine the degree of methylesterification for crude pectin extracted from vegetables, thus providing a means that might be used to determine smaller amounts of pectin more precisely.

\section{Materials and Methods}

Reagents All reagents were of analytical grade. Fluoral$\mathrm{P}$ (Tokyokasei Co., Tokyo) solution was prepared by dissolving $1.0 \mathrm{~g}$ in $10 \mathrm{ml}$ of acetonitrile. Alcohol oxidase (from Pichea pastoris, ICN Biomedical Inc.) was diluted to $40 \mathrm{units} / \mathrm{ml}$ with a $30 \%$ sucrose solution dissolved in $0.1 \mathrm{M}$ phosphate buffer solution ( $\mathrm{pH}$ 6.0). The enzyme unit was calculated according to the value described on the label.

Preparation of crude vegetable pectin Radish root (Raphanus sativus L. cv. Miyasige Aokubi), cabbage (Brassica oleracea L. var. capitata L.), carrot root (Daucus carota L. cv. Kuroda Gosun Ninjin) and broccoli (Brassica olelacea) which were harvested in Okayama, Japan were used as materials.

Pectin was extracted from vegetable tissue slices according to a method described previously (Matsuura et al., 2000). Pectin was extracted 3 times using a $0.035 \mathrm{M}$ ammonium oxalateoxalic acid buffer solution $(\mathrm{pH} 4.2)$ at $80^{\circ} \mathrm{C}$ for $1 \mathrm{~h}$. The extracted solution was immediately cooled in ice water in order to prevent enzymatic modification. The extracted pectin was dialyzed against distilled water at $4{ }^{\circ} \mathrm{C}$ and condensed as necessary. Pectin was precipitated by adding ethanol to the condensed solution (pectin solution: ethanol, 1:4), then filtered through a nylon cloth, and washed with $80 \%, 90 \%$ and $99 \%$ ethanol, respectively. It was finally dried over phosphorous pentoxide in vacuo. The resultant pectin was used as crude vegetable pectin.

Preparation of partially purified citrus pectin Citrus pectin was extracted from the peel of mandarin orange (Natsumikan) as described above. The extracted solution was dialyzed against distilled water and this dialyzed solution was put on a DEAE-Toyopearl column $(2.3 \times 10 \mathrm{~cm}$, equilibrated with $0.05 \mathrm{M}$ acetate buffer, $\mathrm{pH} 6.0$ ) and washed with the $0.05 \mathrm{M}$ acetate buffer ( $\mathrm{pH}$ 6.0). This pectin was eluted with $0.5 \mathrm{M}$ acetate buffer ( $\mathrm{pH} \mathrm{6.0),} \mathrm{then} \mathrm{dialyzed} \mathrm{against} \mathrm{distilled} \mathrm{water} \mathrm{and} \mathrm{con-}$ densed under reduced pressure. Finally, the pectin was precipitated with the addition of four volumes of ethanol and dried as described above.

Pectic acids Citrus pectic acid (Ishizu Co., Ltd, Osaka) was purified by precipitation with $0.1 \mathrm{~N}$ hydrochloric acid solution. The precipitated pectic acid was filtered through a nylon cloth. After filtration, the resulting pectic acid was washed with $0.01 \mathrm{~N}$ hydrochloric acid solution, then $80 \%, 95 \%$ and $99 \%$ ethanol, in that order. The final precipitate was dried in vacuo and dissolved in $0.2 \mathrm{M}$ sodium hydroxide solution.

Vegetable pectic acids were prepared from vegetable pectins by saponification in $0.1 \mathrm{~N}$ sodium hydroxide solution at $4^{\circ} \mathrm{C}$ for $1 \mathrm{~h}$, and the pectic acid which formed was precipitated with ethanol and it was treated the same as described under "Preparation of crude vegetable pectin."

Determination of methanol The conditions for the determination of methanol were according to the method of Hamano et al. (1990). One $\mathrm{ml}$ of methanol solution, $1.5 \mathrm{ml}$ of water, and $2.5 \mathrm{ml}$ of $0.4 \mathrm{M}$ phosphate buffer $(\mathrm{pH} 6.0)$ were transferred to a test tube $(18 \mathrm{~mm} \times 150 \mathrm{~mm})$, mixed, then $50 \mu \mathrm{l}$ ( 2 units) of the diluted alcohol oxidase solution and $0.1 \mathrm{ml}$ of Fluoral-P solution were added. The reaction mixtures were allowed to stand at room temperature for $20 \mathrm{~min}$ with occasional stirring. Immediately after the reaction time, the absorbancy was measured spectrophotometrically at $410 \mathrm{~nm}$ (Hitachi Spectrophotometer 2000).

The present method for determination of methanol was compared with that of Klavons \& Bennett (1986), which was an alcohol oxidase method. The color of formaldehyde was developed with freshly distilled 2,4-pentenedione at $58-60^{\circ} \mathrm{C}$, then absorbancy was measured at $410 \mathrm{~nm}$.

Determination of methanol with addition of pectic acid and copper sulfate The determination of methanol when added to citrus pectic acid and copper sulfate was done as follows: an equal volume of methanol solution and pectic acid solution (concentration was $0.05 \%, 0.10 \%$ or $0.20 \%$ ) which contained $0.2 \mathrm{M}$ sodium hydroxide were mixed. Copper sulfate solution $\left(\mathrm{CuSO}_{4} \cdot 5 \mathrm{H}_{2} \mathrm{O}, 1.0 \%, \mathrm{w} / \mathrm{v}\right)$ of $0.5 \mathrm{ml}$ was added to $1 \mathrm{ml}$ of the methanol solution which contained pectic acid, mixed, allowed to stand for $3 \mathrm{~min}$, and then centrifuged $(5,000 \times \mathrm{g})$ for 3 min. The supernatant was diluted 10 times with water. The final amount of authentic methanol was diluted to $1 / 30$ of the methanol used in the beginning. The diluted solutions were used as the standard solution (control). The conditions for methanol determination were those described under "Determination of methanol."

Determination of degree of methylesterification of crude pectin The crude pectin, which was dissolved by $0.05 \%-$ $0.10 \%$, was saponified in $0.1 \mathrm{M}$ sodium hydroxide solution at $4^{\circ} \mathrm{C}$ for $60 \mathrm{~min}$ in a sealed tube. One $\mathrm{ml}$ of the saponified pectin solution and $0.5 \mathrm{ml}$ of $1.0 \%$ copper sulfate solution were mixed in a centrifuging tube, allowed to stand for $3 \mathrm{~min}$, and then centrifuged $(5,000 \times g)$ for $3 \mathrm{~min}$. The supernatant was diluted with distilled water containing approximately $200-2,000 \mathrm{nmol}$ of anhydrogalacturonic acid. One $\mathrm{ml}$ of the diluted solution was used for the determination of methanol. The degree of methylesterification of pectin was expressed as mol percent of anhydrogalacturonic acid residue $(\mathrm{mol} \%=\mathrm{mol}$ of methanol $\times 100$ / mol of anhydrogalacturonic acid).

The exact concentration of pectin was determined using the saponified and diluted pectic acid solutions from the method of Fillisetti-Cozzi \& Carpita (1991). The amount of pectin was expressed as anhydrogalacturonic acid residue. Galacturonic acid (Sigma Co., USA) was used as a standard substance.

Investigation of the amount of copper sulfate required to remove the inhibitory factor Copper sulfate solutions of $0.1 \%, 1.0 \%$ or $3.0 \%$ were added to the crude pectin solution 
Table 1. Determination of methanol with pectic acid and copper sulfate

\begin{tabular}{|c|c|c|c|c|c|c|c|c|}
\hline \multirow{3}{*}{$\begin{array}{l}\text { Amount of methanol } \\
(\mathrm{nmol})\end{array}$} & \multicolumn{8}{|c|}{ Optical density } \\
\hline & \multirow{2}{*}{$\begin{array}{c}\text { Control (without copper sulfate } \\
\text { and pectic acid) }\end{array}$} & \multicolumn{6}{|c|}{ Concentration of pectic acid results $(\%)$} & \multirow[t]{2}{*}{ Mean $\pm S D$} \\
\hline & & \multicolumn{3}{|c|}{ Citrus } & Carrot root & Cabbage & Radish root & \\
\hline 104 & $0.140 \pm 0.003$ & 0.138 & 0.135 & 0.136 & & & & \\
\hline 208 & $0.284 \pm 0.004$ & 0.279 & 0.272 & 0.285 & 0.284 & 0.281 & 0.277 & $0.281 \pm 0.003^{*}$ \\
\hline 521 & $0.721 \pm 0.008$ & 0.709 & 0.723 & 0.728 & 0.694 & 0.707 & 0.689 & $0.697 \pm 0.008 *$ \\
\hline 1042 & $1.427 \pm 0.011$ & 1.397 & 1.426 & 1.398 & 1.391 & 1.435 & 1.385 & $1.404 \pm 0.023 *$ \\
\hline
\end{tabular}

The resultant concentration of copper sulfate was $0.33 \%$. The values with no addition of pectic acid are average of three experiments: the other values are average of two experiments. * These values are the average and standard deviation among values of carrot root, cabbage and radish root.

Table 2. Determination of methylesterification of crude pectin with and without addition of copper sulfate.

\begin{tabular}{|c|c|c|c|c|c|c|}
\hline & Copper sulfate & Broccoli & Cabbage & Carrot root & Radish root & Citrus* \\
\hline Method of Hamano et al. (1990) & without & $32.5 \pm 0.9$ & $42.6 \pm 0.4$ & $41.5 \pm 2.2$ & $45.8 \pm 0.4$ & $58.5 \pm 1.0$ \\
\hline Modified & with & $44.6 \pm 1.4$ & $53.9 \pm 2.4$ & $57.5 \pm 2.5$ & $62.8 \pm 1.6$ & $58.1 \pm 0.6$ \\
\hline Method of Klavons \& Bennett (1986) & without & $31.3 \pm 1.8$ & $43.2 \pm 4.2$ & $47.1 \pm 2.4$ & $48.5 \pm 3.4$ & $57.7 \pm 3.7$ \\
\hline Modified & with & $46.7 \pm 2.2$ & $57.3 \pm 2.1$ & $58.8 \pm 2.0$ & $63.7 \pm 1.5$ & $57.3 \pm 2.9$ \\
\hline
\end{tabular}

The values are expressed as mol\% (Mean $\pm \mathrm{SD}, n=3$ ). The amounts of pectin used in all of the alcohol oxidase methods were 596.5 (broccoli), 532.7 (cabbage), 404.8 (carrot root), 511.0 (radish root) and 334.7 (citrus) nmol, respectively. There was no significant difference between the values of the modified method of Hamano et al. and the modified method of Klavons and Bennett (with copper ion). There were significant differences between the values determined with and without copper sulfate $(p<0.001)$. *Citrus pectin (partially purified pectin) was used for comparison of the determination values.

$(0.2 \%)$ of cabbage as described under "Dermination of the degree of methylesterification of crude pectin". Pectin had been saponified as described above. Methanol in the mixed solution, after being diluted 20 times with water, was also determined as above.

Statistical analysis Means of determination values were compared using Student's $t$-test.

\section{Results and Discussion}

Determination of methanol with pectic acid and copper sulfate (modified method) The results when $0.025 \%$ to $0.10 \%$ citrus pectic acid or $0.10 \%$ crude vegetable pectic acids and copper sulfate (resultant concentration of $0.33 \%$ ) were added are shown in Table 1. The standard deviation of optical density was small indicating methanol could be determined precisely. For example, the differences in optical density without and with the addition of citrus pectic acid and copper sulfate were $0.004(104 \mathrm{nmol})$ and $0.020(1042 \mathrm{nmol})$, respectively.

It was found that the addition of citrus pectic acid $(0.025 \%$ $0.1 \%)$ and copper sulfate $(0.33 \%)$ did not affect the values of the control (without either substance). There was no significant difference between corresponding values using the Student's $t$ test (all $p$ values $<0.05$ ). In the same manner, there was no difference between the addition of $0.1 \%$ crude vegetable pectic acid and copper sulfate and control. Thus, it appears that the presence of citrus pectic acid or crude vegetable pectic acid and copper sulfate did not affect the intensity of optical density of methanol using the modified conditions.

Investigation of amount of copper sulfate The optical density for determination of methanol of crude pectin from cabbage in the resultant concentration of $0.1 \%, 1.0 \%$ or $3.0 \%$ of copper sulfate was $0.250,0.277$ and 0.277 (an average of 2 experiments), respectively. Therefore, a sufficient amount of copper sulfate to remove the inhibitory factor was found to be $0.5 \mathrm{ml}$ of $1.0 \%$ copper sulfate solution to $1 \mathrm{ml}$ of the saponified pectin solution. The resultant solution was $0.33 \% \quad \mathrm{CuSO}_{4}$ $5 \mathrm{H}_{2} \mathrm{O}$.

Determination of methylesterification of crude pectin with or without addition of copper sulfate The degree of methylesterification of crude pectin (vegetables) determined by the four methods is compared in Table 2. With no copper sulfate precipitation, the degree of methylesterification was $32.5 \%-45.8 \%$ (broccoli-radish root, respectively) by the method of Hamano et al. (1990), and 31.3\%-48.5\% (broccoli-radish root, respectively) by the method of Klavons \& Bennett (1986).

When the copper sulfate was added to both alcohol oxidase methods, the degrees of methylesterification were $44.6 \%-$ $62.8 \%$ (broccoli-radish root) by the modified Hamano method (1990) and $46.7 \%-63.7 \%$ (broccoli-radish root) by the modified method of Klavons \& Bennett (1986). The determination values were significantly higher (all $p$ values $<0.001$ ) than without copper sulfate precipitation. Differences in the degree of methylesterification (mean values) with or without copper sulfate were $11.3 \%-17.0 \%$ (cabbage-radish root) by the method of Hamano et al. (1990) and 11.7\%-15.2\% (carrot root-radish root) by that of Klavons \& Bennett (1986). Therefore, with the methods that did not use copper sulfate, the values of the degree of methylesterification decreased.

Oxalate was removed by dialysis; pectin and the copper sulfate did not affect the value, as described above. Therefore, it appears that some inhibitory factor was present in the crude pectin from vegetables, and this factor was apparently removed by the addition of copper sulfate under the alkaline condition. It is presumed that this inhibitory factor was a high molecular substance, or, if it was a low molecular substance, it adhered to the pectin, causing it to be precipitated with the pectic acid and copper hydroxide under the alkaline condition. This inhibitory factor could not be removed sufficiently, however, under the acidic condition.

Therefore, there was no significant difference in the values 
between the method of Hamano et al. (1990) and that of Klavons \& Bennett (1986), but it was learned that copper sulfate must be added to remove the inhibitory factor, and thus adding it may make the determination of smaller amounts of pectin more accurate.

\section{References}

Albersheim, P., Neukom, H. and Duel, H. (1960). Splitting of pectin chain molecules in neutral solution. Arch. Biochem. Biophys., 90, 4651 .

Bartolome, L.G. and Hoff, J.E. (1972a). Gas chromatographic methods for the assay of pectin esterase, free methanol, and methoxy groups in plant tissues. J. Agric. Food Chem., 20, 262-266.

Bartolome, L.G. and Hoff, J.E. (1972b). Firming of potatoes: Biochemical effects of preheating. J. Agric. Food Chem., 20, 266-270.

Braccini, I. and Perez, S. (2001). Molecular basis of $\mathrm{Ca}^{2+}$-induced gelation in alginates and pectins: the egg-box model revisited. Biomacromolecules, 2, 1089-1096.

Compton, B.J. and Purdy, W.C. (1980). Fluoral-P, a member of a selective family of reagents for aldehyde. Anal. Chim. Acta, 119, 349-357.

Filisetti-Cozzi, T.M.C.C. and Carpita, N.C. (1991). Measurement of uronic acids interference from neutral sugars. Anal. Biochem., 197, 157-162.

Fuchigami, M. (1986). Relationship between maceration and pectic change of Japanese radish roots during cooking (in Japanese). Kaseigakuzashi (J. Home Econ. Jpn.), 37, 1029-1038.

Fuchigami, M. (1987). Relationship between pectic compositions and the softening of the texture of Japanese radish roots during cooking. $J$. Food Sci., 52, 1317-1320.

Hamano, T., Mitsuhashi, Y., Aoki, N. and Yamamoto, S. (1990). Enzymic method for the spectrophotometric determination of aspartame in beverages. Analyst, 115, 435-439.

Hatanaka, C. and Ozawa, J. (1966). Enzymic degradation of pectic acid Part IV. Action of carrot exopolygalacturonase on the pectic acids prepared by saponification of pectin with alkali and with pectinase (in Japanese). Nippon Nogeikagaku Kaishi (Jpn. Soc. Biosci. Biotech.
Agrochem.), 40, 421-428.

Hou, W-C. and Chang, W-H. (1996). Pectinesterase-catarized firming effects during precooking of vegetables. I. Food Biochem., 20, 397 416.

Klavons, J.A. and Bennett, R.D. (1986). Determination of methanol using alcohol oxidase and its application to methyl ester content of pectins. J. Agric. Food Chem., 34, 597-599.

Kravtchenko, T.P., Arnold, I., Voragen, A.G.I. and Pilnik, W. (1992) Improvement of the selective depolymerization of pectic substances by chemical $\beta$-elimination in aqueous solution. Carbohydr: Poly., 19 237-242.

Lee, M. and Macmillan, D. (1968). Mode of action of pectic enzymes. I. Purification and certain properties of tomato pectinase. Biochemistry 7, 4005-4010.

Matsuura, Y., Matsubara, K. and Fuchigami, M. (2000). Molecular composition of onion pectic acid. J. Food Sci., 65, 1160-1163.

McColloch, R.J. and Kertesz, Z.I. (1947). Pectic enzymes. III. A comparison of fungal pectin-methylesterase with that of higher plants, especially tomatoes. Arch. Biochem., 13, 217-229.

McFeeters, R.F. and Armstrong, S.A. (1984). Measurement of pectin methylation in plant cell wall. Anal. Biochem., 139, 212-217.

Prakash, M.D. and Brinson, K. (1984). Plant cell walls. Adv. Carbohydr. Chem. Biochem., 42, 264-382.

Renard, C.M.G.C. and Thibault, J.F. (1996). Pectin in mild alkaline conditions: $\beta$-elimination and kinetic of determination. In "Progress in Biotechnology 14 Pectins and Pectinases," ed. by J. Visser and A.G.J. Voragen, Elsevier Science, Amsterdam, pp. 603-608.

Voragen, A.G.J., Shols, H.A. and Pilnik, W. (1986). Determination of the degree of methylation and acetylation of pectin by h.p.l.c. Food Hydrocolloids, 1, 65-70.

Voragen, A.G.J., Pilnik, W., Thibault, J.-F., Axelos, M.A.V. and Renard, M.G.C. (1995). Pectins. In "Food Polysaccharides and Their Applications," ed. by A.M. Stephen. Marcel Decker, Inc., New York, Basel, and Hong Kong, pp. 287-339.

Wojiciechowski, C.L. and Fall, R. (1996). A continuous fluorometric assay for pectin methylesterase. Anal. Biochem., 237, 103-108. 